\title{
perifèria
}

Número 18, junio 2013

http://revistes.uab.cat/periferia

\section{La fractura política de México en Atempan}

Autor: Jose Luis Molina ${ }^{1}$

\section{Neptalí Ramírez Reyes (2012). La fractura política de México en Atempan, Puebla. Movimiento ciudadano y redes sociales. Puebla: CEPDH.}

Los buenos libros, tanto en la literatura como en la antropología, tienen la virtud de poseer al lector independientemente de su voluntad y abandonarlo solamente cuando éste ha sido conmovido en sus prejuicios y convicciones; o bien cuando éste tiene la certeza que no solamente ha sido testigo mudo de un caso singular, sino que ha estado cerca (todo lo cerca que se puede estar) de los engranajes que mueven el mundo. Este es el caso de La fractura política de México en Atempan.

Con este libro Neptalí Ramírez Reyes hace en primer lugar un acto de reciprocidad con la comunidad que lo acogió, devolviendo con su relato y su análisis, una memoria que ciertamente no caerá nunca en el olvido; en segundo lugar, nos señala una fractura profunda de la legitimidad política mexicana, no desde la simple y honesta denuncia de los hechos, sino desde el análisis académico, riguroso y documentado, de una investigación doctoral.

Si Neptalí quería devolver el regalo que le hicieron abriéndole las puertas de sus casas y de sus vidas, lo ha hecho con creces; si Neptalí quería hacer una aportación al conocimiento de los mecanismos de movilización social en poblaciones indígenas, mostrando las interrelaciones entre las esferas religiosa, cívica y política, lo ha hecho también.

${ }^{1}$ El presente texto corresponde al prólogo del libro, realizado por el Dr. Jose Luis Molina (Universitat Autònoma de Barcelona). 


\section{perifèria}

Número 18, junio 2013

http://revistes.uab.cat/periferia

Nunca pude imaginar cuando era profesor de aquel becario Ford disciplinado y callado, recién llegado a Barcelona, que llevase una carga tan pesada entre las manos. A través de los artículos y trabajos que hemos ido compartiendo, sabía de su interés por Atempan, por los movimientos sociales, por el complejo religiosoritual del sistema de cargos, por las redes sociales, a las que tengo el privilegio de haberlo introducido..., pero hasta que no he leído el libro no me he dado cuenta de toda la profundidad de su empeño. No puedo negar que siempre he sido severo con él, pues nuestro oficio a menudo olvidado es el desapego de todo menos de la verdad, incluyendo a las personas que queremos y a los lugares que nos dejan forman parte de ellos..., y siendo todo el mérito suyo, veo que esta prudencia atraviesa todo el libro y le da un valor científico además de testimonial. Buen trabajo, Neptalí.

Antes de dar paso a la descripción y análisis de los hechos de Atempan de 2006 me gustaría hacer dos consideraciones al lector. La primera de ellas es que el libro que tiene entre las manos sigue la estela de la tradición académica británica llamada Análisis situacional, según la cual, a partir de un acontecimiento (como una fiesta o la ocupación pacífica de un Ayuntamiento) se intenta reconstruir el complejo cultural y las tensiones existentes. Los ejemplos que tenemos en la literatura antropológica son deslumbrantes y este enfoque permite de una manera impresionista acercarse tanto a la correlación de fuerzas institucionales, como a las fracturas existentes. La segunda consideración es la estrategia expositiva del autor, el cual a partir de una introducción histórica presenta de forma alternada el dualismo sistema comunitario-sistema partidario. En el lado comunitario están los valores de la cohesión y la legitimidad. En el lado de los partidos políticos el clientelismo y la corrupción. Así, la descripción del sistema de cargos (ino se pierda ese capítulo!) muestra cómo el complejo ritual tradicional sigue cumpliendo sus funciones de cohesión social, de legitimidad local y de fondo de recursos de todo tipo que, en momentos de crisis, permite su movilización espontánea, despertando en personas humildes y sencillas, líderes decididos y valientes. La resistencia de Atempan no se puede explicar sin la fuerza de las tradiciones. La dura y seca descripción de los hechos y el análisis de las redes de relaciones de las 


\section{perifèria}

Número 18, junio 2013

http://revistes.uab.cat/periferia

organizaciones y entidades participantes en el conflicto muestran cómo esta dualidad no es un recurso retórico, sino un divorcio rotundo.

Y poca cosa más. Me guardo mis dardos envenenados para el propio Neptalí, para hacer que su próximo trabajo sea todavía mejor si cabe; me enorgullezco de haber compartido ambiciones intelectuales con una persona que ha hecho lo que pocos han conseguido: poner el nombre de un lugar en el acervo intelectual de nuestro tiempo, Atempan. 